\title{
Postpartum Health Care Seeking Behaviour among the Rural Women in Bangladesh
}

\author{
Mithun $\mathrm{S}^{1}$, Irfan $\mathrm{SMN}^{2}$ \\ DOI:https://doi.org/10.3329/jafmc.v16i2.55306
}

\begin{abstract}
Introduction: Pregnancy and childbirth is an important event in the life cycle of women and their health during this period is very much vital for the mother and children. Maternal mortality ratio (MMR) of a country is an important indicator of the overall health status of mother.
\end{abstract}

Objectives: To assess the health care seeking behaviour of postnatal women in rural Bangladesh.

Materials and Methods: This cross sectional study was conducted at Chaturia in Dhamrai upazilla of Dhaka district from January 2019 to March 2019 among purposively selected 196 rural women of reproductive age who had at least one living child. Data were collected by face-to-face interview using pretested questionnaire.

Results: Among 196 respondents average monthly family income was 12561 Taka with SD of 10462 taka. Majority of them were housewives and about two-third (64.8\%) were educated above secondary level. $70.9 \%$ respondents had their delivery of last child in a government health care center and $37.8 \%$ deliveries were conducted by nurses which was followed by government doctors (36.2\%). Majority (62.2\%) had their health checkup within 42 days, $59.2 \%$ of them had checkup for three or more times and the checkup were done by government doctors (60.2\%). $47.1 \%$ of the respondents experienced high grade fever as postpartum complication. Statistically significant association $(p<0.05)$ were revealed between age group of the respondents with health personnel conducted deliveries and also between educational level of the respondents with place of delivery of last child.

Conclusion: Awareness, motivation and infrastructural development play a vital role in utilizing the government healthcare services by the postnatal women in rural Bangladesh.

Key-words: Healthcare seeking behavior, Maternal Mortality Ratio, Postnatal Women.

\section{Introduction}

Pregnancy and childbirth is an important event in the life cycle of women and their health during this period is very much vital for the mother and children ${ }^{1}$. Maternal health has now, become a global concern. Through appropriate maternal health services, the lives of millions of women in reproductive age can be saved. Maternal mortality is still very high specially in developing countries despite tremendous effort to provide appropriate maternal health service. Every day, approximately 800 women die from preventable causes related to pregnancy and childbirth and $99 \%$ of all maternal deaths occur in developing countries ${ }^{1}$.

The components of postpartum care include: prevention, early detection and treatment of complications and diseases, the provision of advice and services on breastfeeding, birth spacing, immunization and maternal nutrition. Recent study revealed that nearly half a million women and girls needlessly die as a result of complications during pregnancy, child birth or within six weeks following delivery ${ }^{1}$. As per the guideline of World Health Organizations (WHO), there has to be at least four visits for each postnatal mother i.e. at six to twelve hours after birth, at three to six days, at six weeks, and at six months ${ }^{2}$. These postnatal check-up depends on various factors like age, education, birth order and wealth quintile of the mother. It has been observed that because of many socio-economic and cultural reasons, a good number of postnatal mothers in rural Bangladesh avoid availing the facilities for postnatal care. For this, women are being deprived of government health services that results in huge maternal and neonatal death. A conventional postnatal care includes routine observation and examination of vaginal blood loss, uterine involution, blood pressure and body temperature measurement, counseling on breastfeeding and advice on nutrition during breastfeeding, newborn care practices, and family planning and referral for complications (if any) ${ }^{2}$. In Bangladesh occurrence of a postnatal checkup for mothers within 2 days of delivery increased from $20 \%$ in 2007 to $34 \%$ in 2014 and then to the current level of $52 \%$ in $2017^{3}$.

Maternal mortality ratio (MMR) of a country is an important indicator of the overall health status of its mothers. High MMR signifies the weakness of the health system to provide effective services and care for the population. The target of the Sustainable Development Goal for Bangladesh was to reduce MMR from 181 in 2015 to 70 in 2030 (current MMR as on 2019 is 165 deaths per $100,000$ live births $)^{4}$. Despite the government's serious commitment to deliver health facilities to people's doorsteps, the utilization of health services is still far below the acceptable standard ${ }^{5}$. Whenever any health problem arises, the first step to cure that problem is the health care seeking behavior. Health care seeking behavior can be

1. Lt Col Sangita Mithun, MBBS, MPhil (Physiology), Instructor Physiology, Armed Forces Medical College, Dhaka (E-mail: sangitamithun@yahoo.com) 2. Lt Col SM Nurul Irfan, MBBS, MPH (HM), Student Officer, MPhil (PSM), Armed Forces Medical Institute, Dhaka. 
defined as the sequence of curative actions that an individual seeks to cure perceived ill health ${ }^{6}$. In this study we aim to assess the health care seeking behavior of postnatal women in rural Bangladesh.

\section{Material and Methods}

This cross sectional study was conducted at Chaturia in Dhamrai upazilla of Dhaka district from January 2019 to March 2019 among purposively selected 196 rural women of reproductive age who had at least one living child. Data were collected through face to face interview by pretested semi structured questionnaire. Informed written consents were taken from all the respondents. Ethical issue was addressed. Data processing and analysis were done by SPSS version 23. Frequency, percentage, mean and standard deviation were used for descriptive statistics, chi square $(X 2)$ were used to see the association. Level of significance were set at $p<0.05$.

\section{Results}

Majority of the respondents $(69.9 \%)$ belongs to the age group 25-34 years which is followed by $<25$ years (21.9\%). Mean age $( \pm S D)$ was $26.5( \pm 5.7)$ years. About $86.7 \%$ were Muslim and $64.8 \%$ qualified up to secondary level which is followed by primary level (18.9\%). Almost $41.8 \%$ of the respondents gave history of monthly family income of $10001-20000$ taka and around $39.3 \%$ of them had family income $<10000$ taka and rest of them had family income of $>20001$ taka. Average monthly family income was 12561 taka with SD of 10462 taka. (Table 1).

Majority of the respondents (70.9\%) had their delivery at government health center which was followed by home delivery (27.0\%) (Figure-1). 37.8\% deliveries were conducted by nurse which is followed by government doctors (36.2\%), and $26 \%$ of the delivery conducted by trained birth attendants (Figure-2). About $62.2 \%$ of the respondents had their health checkup within 42 days after delivery and majority (59.2\%) of them visited 4 times or more for the health checkup. It was revealed that $60.2 \%$ of the respondent's health checkup was done by the government doctors which was followed by trained birth attendant. About $80.1 \%$ respondents reported to the government health facilities (Upazilla health complex) for their health checkup and rest of the respondents chose other healthcare facilities like Union sub-center (4.6\%), family welfare center (4.6\%) and Non-government clinic (10.7\%). 53.1\% respondents sought health checkup to ensure about health condition after delivery, $17.3 \%$ thought it was necessary and $16.8 \%$ due to health problems (Table-II). Regarding complications majority (25.9\%) of the respondents experienced high grade fever which was followed by lower abdominal pain (20.4\%), urinary tract infection (17.6\%), genital tract infection (13.3\%), cervical/perineal tear (11\%), postpartum hemorrhage (1.6\%) etc (Figure-3).
The association between age group of the respondents with health personnel conducted deliveries revealed that almost equal number of the respondents' deliveries were conducted by the trained birth attendants, nurse and government doctors falls in the 25-34 years of age and the association was statistically significant $(p<0.05)$ (Table-III). The association between educational qualification of the respondents with place of delivery of last child revealed that most of the secondary level qualified respondents had their last delivery at government health center followed by home delivery and statistically significant association $(p<0.05)$ was found among them (Table-IV).

Table-I: Socio-demographic characteristics of the respondents $(n=196)$

\begin{tabular}{|c|c|c|}
\hline Characteristics & Number & Percentage \\
\hline \multicolumn{3}{|c|}{ Age of respondents (years) } \\
\hline$<25$ & 43 & 21.9 \\
\hline $25-34$ & 137 & 69.9 \\
\hline $35-45$ & 16 & 8.2 \\
\hline Mean (SD) & \multicolumn{2}{|c|}{$26.5( \pm 5.7)$ years } \\
\hline \multicolumn{3}{|l|}{ Religion } \\
\hline Islam & 170 & 86.7 \\
\hline Hindu & 26 & 13.3 \\
\hline \multicolumn{3}{|c|}{ Educational level of respondents } \\
\hline No formal education & 19 & 9.7 \\
\hline Primary level & 37 & 18.9 \\
\hline Secondary level & 127 & 64.8 \\
\hline Higher Secondary level & 13 & 6.6 \\
\hline \multicolumn{3}{|l|}{ Family income (Taka) } \\
\hline$\leq 10000$ & 77 & 39.3 \\
\hline $10001-20000$ & 82 & 41.8 \\
\hline $20001-25000$ & 30 & 15.3 \\
\hline$\geq 25001$ & 7 & 3.6 \\
\hline Mean (SD) & \multicolumn{2}{|c|}{ 12561( \pm 10462$)$ Taka } \\
\hline \multicolumn{3}{|c|}{ Occupational status of respondents } \\
\hline Housewife & 138 & 70.4 \\
\hline Day laborer & 32 & 16.3 \\
\hline Others & 26 & 13.3 \\
\hline \multicolumn{3}{|c|}{ Number of family members } \\
\hline $3-5$ & 106 & 54.1 \\
\hline 6-8 & 57 & 29.1 \\
\hline$\geq 9$ & 33 & 16.8 \\
\hline Mean (SD) & \multicolumn{2}{|l|}{$4.9( \pm 1.9)$} \\
\hline
\end{tabular}




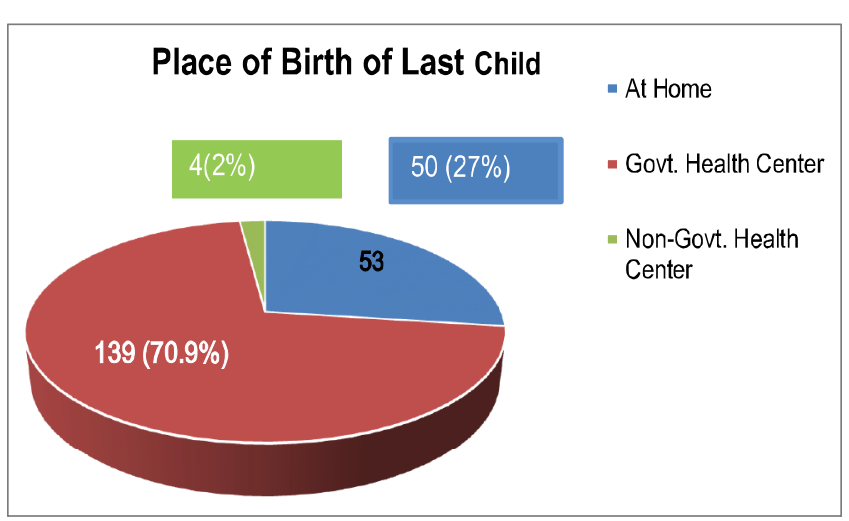

Figure-1: Distribution of respondents by place of birth of last child $(n=196)$

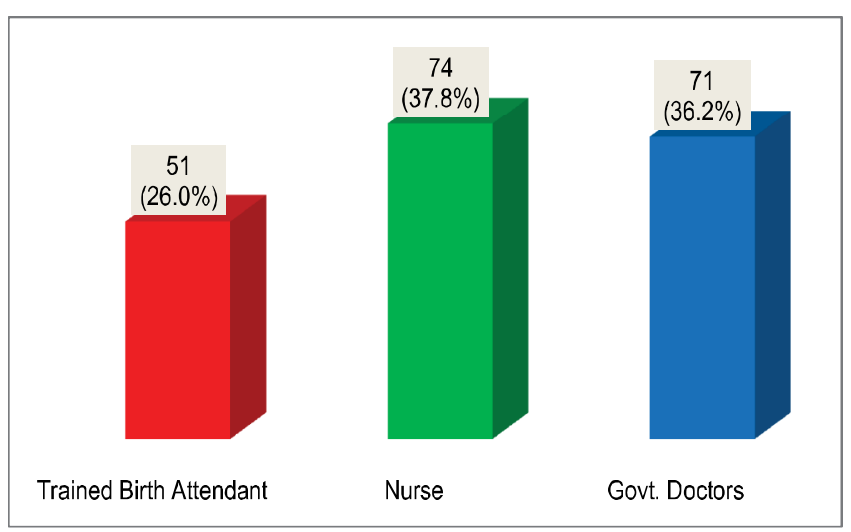

Figure-2: Distribution of deliveries conducted by health personnel $(n=196)$

Table-II: Health checkup related information $(n=196)$

\begin{tabular}{|c|c|c|}
\hline Characteristics & Frequency & Percentage \\
\hline \multicolumn{3}{|l|}{ Health Checkup within 42 Days ( $n=196)$} \\
\hline Yes & 122 & 62.2 \\
\hline No & 74 & 37.8 \\
\hline \multicolumn{3}{|l|}{ Frequency of Health Checkup ( $n=196)$} \\
\hline Twice & 56 & 28.6 \\
\hline Thrice & 24 & 12.2 \\
\hline 4 times and more & 116 & 59.2 \\
\hline \multicolumn{3}{|l|}{ Health Checkup done By } \\
\hline Trained Birth Attendant & 42 & 21.4 \\
\hline Un-trained Birth Attendant & 4 & 2.0 \\
\hline Nurse & 32 & 16.3 \\
\hline Govt. Doctor & 118 & 60.2 \\
\hline \multicolumn{3}{|l|}{ Place of Health checkup } \\
\hline Upazilla health complex & 47 & 80.1 \\
\hline Union sub center & 9 & 4.6 \\
\hline Family welfare center & 9 & 4.6 \\
\hline Non-govt. clinic & 21 & 10.7 \\
\hline \multicolumn{3}{|l|}{ Reason for seeking health care } \\
\hline $\begin{array}{l}\text { To ensure about health condition after } \\
\text { delivery }\end{array}$ & 104 & 53.1 \\
\hline Everybody marks it as necessary & 34 & 17.3 \\
\hline For health problem & 33 & 16.8 \\
\hline Others & 25 & 12.8 \\
\hline Total & 196 & 100.0 \\
\hline
\end{tabular}

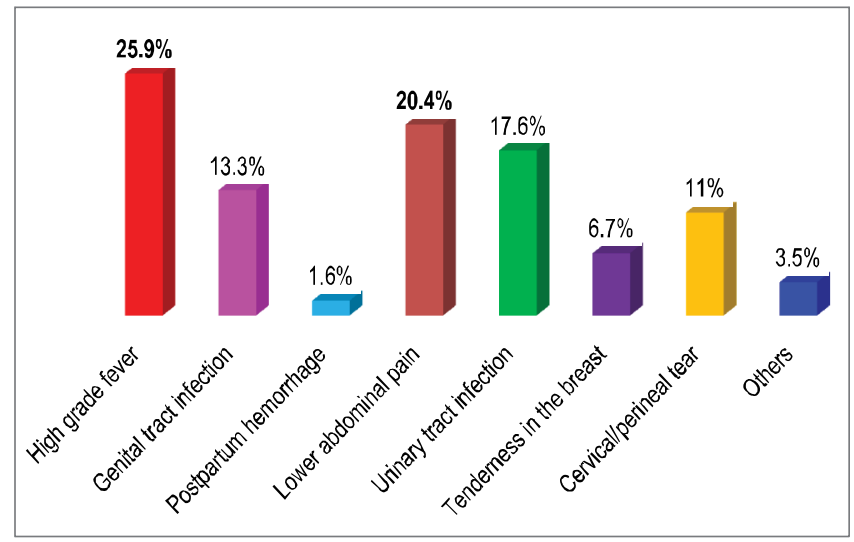

Figure-3: Complications after delivery $(n=196)$

Table-III: Association between age group with health personnel conducted the deliveries $(n=196)$

\begin{tabular}{|c|c|c|c|c|c|c|}
\hline \multirow[t]{2}{*}{ Age group } & \multicolumn{3}{|c|}{ Delivery Conducted By } & \multirow[t]{2}{*}{$x^{2}$} & \multirow[t]{2}{*}{ df } & \multirow[t]{2}{*}{$\mathrm{p}$} \\
\hline & $\begin{array}{c}\text { Trained Birth } \\
\text { Attendant }\end{array}$ & Nurse & $\begin{array}{l}\text { Govt. } \\
\text { Doctors }\end{array}$ & & & \\
\hline $15-24$ & 0 & 18 & 25 & \multirow{3}{*}{29.09} & \multirow{3}{*}{4} & \multirow{3}{*}{$.000^{*}$} \\
\hline $25-34$ & 43 & 48 & 46 & & & \\
\hline $35-45$ & 8 & 8 & 0 & & & \\
\hline
\end{tabular}

Table-IV: Association between educational qualification with place of birth of last child ( $n=196)$

\begin{tabular}{|l|c|c|c|c|c|c|}
\hline $\begin{array}{l}\text { Educational } \\
\text { Qualification of the } \\
\text { Respondents }\end{array}$ & \multicolumn{2}{|c|}{ Place of Birth of Last Child } & \multirow{2}{*}{$X^{2}$} & $d f$ & $p$ \\
\cline { 2 - 5 } & $\begin{array}{c}\text { At } \\
\text { Home }\end{array}$ & $\begin{array}{c}\text { Govt. Health } \\
\text { Center }\end{array}$ & $\begin{array}{c}\text { Non-Govt. Health } \\
\text { Center }\end{array}$ & & & \\
\hline No formal education & 4 & 15 & 0 & & \multirow{2}{*}{62.5} & $.000^{\star}$ \\
\hline Primary level & 0 & 37 & 0 & & \\
\hline Secondary level & 49 & 78 & 0 & & \\
\hline Higher Secondary level & 0 & 9 & 4 & & & \\
\hline
\end{tabular}

\section{Discussion}

The study was conducted to assess the postpartum health care seeking behavior of the rural women. In this study, respondents' age, income, religion, family size etc. showed some similarities with national findings of Bangladesh Health and Demographic Survey (BDHS) of $2017^{7}$, the dissimilarities found may be due to regional variation. The sociodemographic data were also found consistent with the study conducted by Kifle D et al. ${ }^{1}$, Nayan SK et al ${ }^{2}$ and Hordofa MA et al ${ }^{8}$.

This study revealed that $70 \%$ deliveries were conducted in the government healthcare center which was dissimilar with the findings by Koeing MA et $\mathrm{a}^{9}$. This dissimilarity may be due to the fact that the study was conducted in the year 2007 and our one was in the year 2019.

In this study, $62.2 \%$ of the respondents had health checkup within 42 days after delivery which was consistent with the report by UNICEF $^{10}$. Almost similar finding was also evident from the study conducted by Nayan SK et $\mathrm{al}^{2}$. In this study, $59.2 \%$ of the respondents received postnatal care for 4 times or more which was dissimilar with the study conducted by Nayan et al². 
It was found from the study that $80.1 \%$ respondents reported to the government health facilities for their health checkup and rest chose other healthcare facilities which was not consistent with finding by Nayan SK et $\mathrm{al}^{2}$. This dissimilarity may be due to the recent improvement of communicational facilities and motivation.

From this study it was revealed that $53.1 \%$ respondents sought health checkup to ensure sound health condition after delivery, $17.3 \%$ sought as they thought it was necessary and $16.8 \%$ sought due to health problems which was almost similar to the findings of the study conducted by Nayan SK et al'2.

In this study as complications $25.9 \%$ of the respondents experienced high grade fever which was followed by lower abdominal pain (20.4\%), urinary tract infection (17.6\%), genital tract infection (13.3\%), cervical/perineal tear (11\%), postpartum hemorrhage (1.6\%) etc. These finding was consistent with the study conducted by Khanum PA et a ${ }^{11}$, Islam MA et al ${ }^{12,13}$.

The study showed a statistically significant association $(p<0.05)$ between age group of the respondents with health personnel conducted deliveries. Here almost equal number of the respondents' deliveries were conducted by the trained birth attendants, nurses and government doctors falls in the 25-34 years of age. A statistically significant association between educational qualification of the respondents with place of delivery of last child $(<0.05)$ was also evident, which was consistent with the report by $\mathrm{UNICEF}^{14}$ and study conducted by Islam MA et $a^{12}$.

\section{Conclusion}

The healthcare seeking behaviour of the postnatal women has quite increased which is evident from the findings of this study; yet it has to be increased further. It is important to note that awareness, motivation and infrastructural development play a vital role in utilizing the government healthcare services by the postnatal women in rural Bangladesh.

\section{References}

1. Kifle D, Azale T, Gelaw YA et al. Maternal health care service seeking behaviors and associated factors among women in rural Haramaya District, Eastern Ethiopia: A triangulated communitybased cross-sectional study. Reproductive health. 2017; 14(1):6.

2. Nayan SK, Begum N, Abid MR et al. Utilization of Postnatal Care Services among the Rural Women in Bangladesh. Northern International Medical College Journal. 2017; 8(2):208-12.
3. National Institute of Population Research and Training (NIPORT) and ICF; 2019. Bangladesh Demographic and Health Survey 2017-18: Key Indicators. Dhaka, Bangladesh, and Rockville, Maryland, USA: NIPORT, and ICF.

4. https://www.sdg.gov.bd/page/indicator-wise/5/429/3/0\#1; accessed on 20 August 2020.

5. Haque MA, Dash SK, Chowdhury MAB. Maternal health care seeking behavior: the case of Haor (wetland) in Bangladesh. BMC public health. 2016; 16(592):1-9.

6. Islam MR, Islam MA, Banowary B. Antenatal and postnatal care seeking behavior in a matrilineal society: A Study on the Garo tribe of Bangladesh. J Fam Welf. 2009; 55(1):62-9.

7. Report of Bangladesh Sample Vital Statistics 2017. Ministry of Planning, Bangladesh. www.bbs.gov.bd; accessed on 12 August 2020.

8. Hordofa MA, Almaw SS, Berhanu MG et al. Postnatal care service utilization and associated factors among women in Dembecha District, Northwest Ethiopia. Science Journal of Public Health. 2015; 3(5):686-92.

9. Koenig MA, Jamil K, Streatfield PK et al. Maternal health and care-seeking behavior in Bangladesh: findings from a national survey. International Family Planning Perspectives. 2007; 33(2):75-82.

10. https://data.unicef.org/country/bgd/; accessed on 20 August 2020.

11. Khanum PA, Quaiyum MA, Islam A et al. Complications of pregnancy and childbirth: knowledge and practices of women in rural Bangladesh. ICDDRB. 2000; 131:1-28.

12. Islam MA, Chowdhury RI, Akhter HH. Complications during pregnancy, delivery, and postnatal stages and place of delivery in rural Bangladesh. Health Care for Women International. 2006; 27(9):807-21.

13. Islam MA, Chowdhury RI, Chakraborty $\mathrm{N}$ et al. Factors associated with delivery complications in rural Bangladesh. The European Journal of Contraception \& Reproductive Health Care. 2004; 9(4):203-13.

14. UNICEF. Maternal and Newborn Health Disparities. Bangladesh. Accessed on 20 August 2020. 